\title{
O PROCESSO EDUCACIONAL INCLUSIVO NO CEFET-RN: UMA LEITURA CRÍTICA DO PROJETO POLÍTICO-PEDAGÓGICO
}

\author{
Fernando Fernandes Gomes \\ Licenciado em Biologia pela UFRN. Graduando em Licenciatura em Física no CEFET- \\ RN. E-mail: fecajueiro@ hotmail.com
}

\section{RESUMO}

$\mathrm{O}$ presente artigo analisa a importância do projeto político-pedagógico (PPP) em um processo de inclusão educacional que vise possibilitar, igualmente a todas as pessoas, o acesso a uma educação de qualidade, considerando os aspectos físicos, sociais e econômicos. Diante disso, este artigo tem como objetivo realizar uma leitura crítica do projeto político-pedagógico do CEFET-RN, que se encontra em construção, avaliando sua contribuição para um processo educacional inclusivo. $\mathrm{O}$ trabalho foi elaborado a partir de uma revisão bibliográfica e da análise do projeto político-pedagógico do CEFET-RN. O estudo revela que esse documento, no que diz respeito ao processo educacional inclusivo, mostra a preocupação da Instituição em estar respaldada em documentos nacionais; em adotar políticas específicas para o ingresso de estudantes de escolas públicas; e em efetivar a prática da inclusão das pessoas com necessidades educacionais especiais (PNEE). Espera-se que este artigo contribua para o término da construção desse importante documento que é o projeto político-pedagógico.

PALAVRAS-CHAVE: CEFET-RN. Educação inclusiva. Inclusão social. Projeto políticopedagógico.

\section{EL PROCESO EDUCATIVO INCLUSIVO EN EL CEFET-RN: UN ANÁLISIS CRÍTICO DEL PROYECTO EDUCATIVO DEL CENTRO}

\section{RESUMEN}

Este artículo analiza la importancia del proyecto educativo de centro en un proceso de inclusión educativa orientado a proporcionar el acceso de todas las personas a una educación de calidad, considerando los medios físicos, sociales y económicos. El artículo se propone a analizar el proyecto educativo de centro del CEFET-RN, que está en construcción, respecto a su carácter inclusivo. Se ha elaborado el texto a partir de una revisión bibliográfica y de análisis documental del proyecto educativo de centro del CEFET-RN. El análisis revela que ese proyecto, en lo que respecta al proceso educativo inclusivo, está orientado a adoptar políticas específicas que privilegien el ingreso de estudiantes de escuelas públicas; asimismo busca tornar efectiva la práctica de incluir personas con necesidades educativas especiales (PNEE). Finalmente, se espera que este artículo contribuya con el perfeccionamiento del proyecto educativo de centro del CEFET$\mathrm{RN}$, actualmente en construcción.

PALABRAS CLAVE: CEFET-RN. Educación inclusiva. Inclusión social. Proyecto educativo de centro. 


\title{
O PROCESSO EDUCACIONAL INCLUSIVO NO CEFET-RN: UMA LEITURA CRÍTICA DO PROJETO POLÍTICO PEDAGÓGICO
}

\section{INTRODUÇÃO}

Pensar nas causas que promovem o processo de exclusão e evasão escolar é tentar entender parte da complexidade que envolve o sistema educacional brasileiro. Logo, é fato que as políticas de inclusão educacional devem ser priorizadas de modo a permitir uma educação pública, gratuita e de boa qualidade a todos. Assim, afirmam Sousa e Corrêa (2002, p.50):

\begin{abstract}
Diante do caos que vivemos no inicio do século XXI, em que grupos cada vez mais poderosos monopolizam a economia e a política, desenvolvendo um insano processo de exclusão e marginalização para $2 / 3$ da humanidade, é imprescindível que a escola procure discutir alternativas capazes de assegurar processos educativos que possibilitem aos oprimidos e explorados formas de inserção e participação em suas práticas.
\end{abstract}

É com base nesse discurso que o objeto de estudo deste artigo se revela. A inserção ou inclusão social que uma escola deve promover aos seus membros, discentes ou não, necessita estar explícita no ambiente escolar, assim como ter existência concreta em seus documentos. Para tanto, o projeto político-pedagógico (PPP) é o principal instrumento que uma escola pode utilizar para nortear a sua prática educativa construída com a participação da sociedade.

Neste artigo, busca-se avaliar o projeto político-pedagógico, em construção, do Centro Federal de Educação Tecnológica do Rio Grande do Norte (CEFET-RN) com relação a sua abordagem sobre a inclusão social dos seus alunos.

Para consolidar esse propósito, proceder-se-á a uma revisão bibliográfica e a uma análise documental. Em relação à primeira, far-se-á uma revisão dos principais conceitos e pressupostos teóricos sobre a inclusão social no âmbito educacional. A partir desse levantamento, será realizada a análise documental do PPP do CEFET-RN utilizando-se de seções e itens extraídos do documento que mostrem relação com o assunto em estudo.

As perspectivas da abordagem sobre a inserção social na área educacional do PPP do CEFET-RN visam colaborar com a construção desse importante documento, uma vez que, ele ainda não fora concluído. Além disso, uma leitura crítica de um dos alicerces das diretrizes pedagógicas dessa instituição - tida como referência no estado do Rio Grande do Norte - permite fazer uma reflexão sobre o projeto, buscando o seu fortalecimento e concretização por meio da identificação de seus pontos fracos e fortes e de sugestões de melhorias.

No entanto, a análise do PPP revela-se apenas uma das formas de avaliar a concretização de um processo inclusivo educacional em uma instituição. Não se pode esquecer de que a inserção social deve ocorrer num todo, tanto de forma legal como de forma física e comportamental. Por isso, após essa análise do PPP, necessita-se sair da esfera documental do CEFET-RN e se envolver no mundo real das ações, relações e edificações humanas, 
avaliando como a população, os recursos humanos e a estrutura física dessa instituição participam do processo de inclusão social.

O teor deste artigo está exposto em mais três seções, além desta inicial, as quais que se inter-relacionam. A abordagem inicia-se com a conceituação e os pressupostos teóricos da inclusão social. Em seguida, comenta-se sobre o trabalho, a sociedade, a ciência e a cultura, componentes privilegiados do universo que promove a existência humana. Com ênfase na sociedade, explora-se a questão da inclusão social como importante processo para a educação em geral e, particularmente, para o PPP, projeto que materializa a intencionalidade educacional das instituições e que, nesse sentido, pode ser um instrumento potencializador da inserção social. Concluindo o desenvolvimento, a última seção avalia o PPP do CEFET-RN buscando cumprir com o objetivo proposto no artigo.

Alguns referenciais teóricos foram fundamentais para a construção deste material. Dentre eles estão Laplane (2006), Mantoan (2007) e Figueira (2006), com teorias ligadas à educação inclusiva. Sobre a importância da sociedade na educação, tem-se Severino (2004). Sousa e Corrêa (2002) com contribuições acerca do PPP e participando da análise do PPP do CEFET-RN, os Parâmetros curriculares nacionais: Adaptações Curriculares, Lei de Diretrizes e Bases da Educação Nacional - LDB e a Política Nacional para Integração da Pessoa com Deficiência.

\section{INCLUSÃO SOCIAL: CONCEITUAÇÃO E SEUS PRESSUPOSTOS}

Inclusão social é um processo pelo qual toda a sociedade sofre uma adaptação que visa incluir, em seus sistemas sociais, cidadãos que dela foram excluídos, "sem distinção de condições lingüísticas, sensoriais, cognitivas, físicas, emocionais, éticas, socioeconômicas" ou qualquer outra situação (BRASIL, 1998, p. 17).

De acordo com Sassaki (apud FIGUEIRA, 2006, p. 1),

O processo de inclusão vem sendo aplicado em cada sistema social. Assim, existe a inclusão na educação, na saúde, na assistência, no lazer, no transporte, etc. Quando isso acontece, podemos falar em educação inclusiva, na saúde inclusiva, na assistência inclusiva, no lazer inclusivo, no transporte inclusivo e assim por diante. Uma outra forma de referência consiste em dizermos, por exemplo, educação para todos, lazer para todos, transporte para todos.

Em 2001, as Diretrizes para a Educação Especial mencionam, pela primeira vez, a inclusão. O documento deu destaque à Declaração de Salamanca (1994), enquanto fonte de inspiração filosófica, e impulsionou a difusão do termo inclusão e, também, divulgou a noção de que todas as crianças devem ser educadas num mesmo ambiente (LAPLANE, 2006, p. 16-17).

Por fim, no início de 2004, a Secretaria de Educação Especial do Ministério da Educação lançou a série Educação Inclusiva, um conjunto de documentos destinados a promover a implementação da política de inclusão escolar. A série é composta de quatro documentos 
que abordam os aspectos filosóficos da inclusão, o papel dos municípios, da escola e da família (LAPLANE, 2006, p. 18-19).

Contudo, o que se observa, na prática, são ações isoladas ao lado de um conjunto de leis e projetos desarticulados e sem impacto que acabam criando uma série de contradições e um fosso entre o discurso e a ação. Para que se fixe o ideal da educação inclusiva, é necessário que as instituições de ensino reflitam, em seu projeto político-pedagógico, o meio físico, social e cultural nos quais se encontram localizadas. Sobre as mudanças nas propostas educacionais de grande parte das escolas, Mantoan (2007, p. 3) afirma que

\begin{abstract}
Para reverter o processo educacional excludente das nossas escolas, entendemos que o papel da escola deve ser revisto, de modo que a instituição passe a se dedicar essencialmente à formação de sujeitos éticos, políticos, justos, cooperativos, autônomos. A verdade é que não há mais tempo a perder para tornar nossos alunos mais humanos e capazes de acompanhar a velocidade do desenvolvimento do saber científico e tecnológico dos nossos dias.
\end{abstract}

Entretanto, nem todas as escolas têm condições de implementar a educação inclusiva, impedindo assim, a entrada de alunos que não atendam às suas expectativas de aprendizagem. Já, diferentemente, nas escolas inclusivas, nota-se uma mudança de postura, de concepções e atitudes por parte de educadores, de pesquisadores, de pais e da comunidade em geral.

\title{
A IMPORTÂNCIA DA INCLUSÃO SOCIAL PARA A EDUCAÇÃO
}

Tome-se como referência o ponto de vista de Severino (2004, p. 26):

Podemos então equacionar a existência humana como se dando mediada pelo tríplice universo do trabalho, da sociedade e da cultura. [...] esses três universos se complementam e se implicam mutuamente, um dependendo do outro, a partir de sua própria especificidade.

Pode-se apreender, através dessa citação, que o processo de inclusão social é de fundamental importância para as relações humanas, pois insere o indivíduo em um determinado grupo social atribuindo-o assim um significado existencial.

A educação, como expressão humana, também se alicerça sobre esse tríplice universo juntamente com a esfera das ciências. Sua constituição, fundamentação e práxis dependem do trabalho, da sociedade e da cultura que os indivíduos envolvidos nela trazem consigo. Dessa forma, o processo de inclusão social na educação é importantíssimo para inserir o sujeito em um ambiente educacional (físico ou não) que lhe permita interagir com a cultura e o conhecimento científico da humanidade, tornando-o parte de uma trama social. Dentro destra trama, ou fora dela, esse mesmo sujeito poderá, por meio da educação, inserir-se também no universo do trabalho e assim externa nele a sua identidade e posição política. 
Severino (2004, p.24) ainda comenta que "a prática produtiva dos homens não se dá plenamente só como trabalho individual: ela é, antropologicamente falando, expressão necessária de um sujeito coletivo, ou seja, a espécie humana só é humana na medida em que se efetiva em sociedade". Essa sentença reforça a importância da inclusão social na educação, quando se trocam as expressões "prática produtiva" e "trabalho" por "prática educativa" e "educação", respectivamente. Sendo assim, fica claro que a educação, como forma de expressão humana, se alicerça nas relações sociais e na inclusão do indivíduo nela.

Nessa perspectiva, as instituições escolares têm como principal orientação para a interação entre trabalho educativo e sociedade, o PPP. Trata-se de um documento que, de acordo com Vasconcellos (apud SOUSA e CORREAA, 2002, p.51), pode ser entendido como a sistematização, nunca definitiva, de um planejamento participativo que se aprimora e se concretiza durante o processo educacional e que define e orienta o tipo de ação educativa que se quer promover. Vasconcellos ainda coloca: "é um instrumento teóricometodológico para a transformação da realidade". Com base nas idéias de Sousa e Corrêa (2002, p.49), o PPP "deve ser concebido no universo do trabalho coletivo e da democratização do espaço escolar", a partir de uma pedagogia e política que procure ouvir, respeitar e avançar com os ideais, as propostas e concepções expressas pelos vários atores envolvidos na prática educativa, sejam eles docentes ou outros integrantes da escola e da comunidade.

Com isso, pode-se atribuir ao PPP, a responsabilidade de promover a inclusão social, numa determinada instituição, de pessoas que estejam a margem desse ambiente ou presentes no seu interior, porém excluídos da participação social.

\section{ANALISANDO O PPP DO CEFET-RN}

Após a análise documental do PPP, decidiu-se destacar algumas seções e itens, para mostrar como está o processo educacional inclusivo no CEFET-RN. Este procedimento foi necessário, pois seria bastante cansativa e longa uma abordagem item por item do PPP, uma vez que o documento analisado, que ainda encontra-se em construção, possui 138 páginas e muitos dos seus itens não trazem, em nenhum momento, nenhuma informação sobre processo educacional inclusivo. Serão comentados os seguintes itens e seções: Concepção institucional de sociedade, cultura (falta), tecnologia (falta), trabalho, educação e ser humano; Os desafios atuais e futuros; Bases sócio-culturais; Bases filosóficas e epistemológicas; Política de inclusão das pessoas com necessidades educacionais especiais - PNEE; Política de educação à distância. A abordagem desses itens e seções será feita com base na fundamentação teórica já realizada no decorrer do artigo, e também por meio de outros documentos de relevância nacional.

\section{Concepção Institucional de Sociedade, Cultura, Tecnologia, Trabalho, Educação e Ser Humano}

O PPP do CEFET-RN (2005, p.30-31) trás a seguinte concepção de cultura: “em seu aspecto pedagógico, a cultura dispõe de todo um instrumental que a faz forte, pois sua presença é constante e imbricada na vida dos indivíduos, desde a tenra idade até a morte, num processo antropológico tonificador de espíritos". De forma semelhante, para Severino (2004, p.25), a cultura mostra-se como prática simbolizadora baseada na construção 
histórica e coletiva do objeto pelos sujeitos em que "o conhecimento individual se dá sobre o fundo de uma experiência radicalmente histórica e coletiva que lhe é anterior e que lhe serve de matriz placentária". Vistas dessa forma, essas concepções de cultura reforçam o argumento sobre a inclusão social e principalmente a inclusão social no campo educacional, uma vez que também é por meio da escola que um sujeito entra em contato com a cultura. Logo, concluiu-se nesta seção, que o CEFET-RN preocupa-se em reconhecer a cultura como um elemento que promove um processo antropológico que tem como conseqüência um processo educacional inclusivo.

\title{
Os Desafios Atuais e Futuros
}

A responsabilidade social com os egressos da educação profissional é um importante desafio que o CEFET-RN possui. Esse desafio

\begin{abstract}
Refere-se, assim, ao poder dessa modalidade educacional de contribuir com o aumento da capacidade de (re)inserção sociolaboral de longa duração dos seus egressos, com a extensão de ofertas de boa qualidade aos coletivos mais desfavorecidos desde o ponto de vista socioeconômico (pouco atendidos atualmente) e com a própria capacitação desses egressos para que, uma vez beneficiados pela educação profissional - EP, possam atuar, de forma competente e ética, como agentes de mudanças orientadas à satisfação das necessidades coletivas, notadamente as das classes menos favorecidas (MOURA, 2000a e b; FREIRE, 1986; 2000a e b; 2001). (CEFET-RN (2005, p.50)
\end{abstract}

É, portanto visível o cuidado do CEFET-RN em realizar um processo educacional que inclua as classes populares. Trata-se, então de uma educação inclusiva que vai além de uma atenção voltada às pessoas com necessidades educacionais especiais, mas também uma atenção voltada às pessoas tidas como "oprimidas". Neste ponto, o PPP do CEFETRN está fortemente baseado principalmente pela pedagogia de Paulo Freire. Ter este autor em suas referências mostra o interesse desta instituição em discutir as questões sociais que envolvem a exclusão de pessoas na nossa atual sociedade neoliberal e a esperança na construção de uma sociedade mais justa e igualitária.

\section{Bases Sócio-Culturais}

A pedagogia assumida pelo CEFET-RN revela-se por meio dos fundamentos e dos princípios existentes em seu currículo. Estes por sua vez estão alicerçados em três bases: as legais, as sócio-culturais e as filosóficas e epistemológicas. Para uma discussão do processo inclusivo educacional, foram destacadas as segundas (conteúdo deste item) e as terceiras bases.

As bases sócio-culturais da pedagogia assumida pelo CEFET-RN condizem com o exposto na terceira seção deste artigo, o PPP como instrumento de inserção social. Um argumento que reforça a afirmação acima é a seguinte transcrição: 
A instituição educacional, portanto, deve estar aberta ao diálogo com os diversos segmentos sociais, com suas ofertas simbólicas e estéticas sejam elas populares, eruditas, ou mesmo massivas, pois apenas dessa forma é possível construir uma escola pluralista e universalista, gestante de sujeitos críticos, democráticos e tolerantes. (CEFET-RN, 2005, p.83)

O fato de uma instituição estar aberta ao diálogo, para realizar uma construção pluralista e universalista, é um dos grandes passos para que a elaboração do seu PPP se efetive. É ouvindo e respeitando as identidades, os ideais, as concepções e as propostas das várias pessoas envolvidas na sua prática educativa que esse diálogo será enraizado e favorecerá um processo educativo inclusivo.

\title{
Bases Filosóficas e Epistemológicas
}

É neste item que se encontra, como base epistemológica, a política da igualdade. Ela é um ótimo exemplo da importância e do caráter político que um PPP deve ter. Assim está no PPP do CEFET-RN (2005, p.92):

\begin{abstract}
A política da igualdade deve ser buscada no sentido de atender a todos os grupos que busquem a Instituição, independentemente de origem socioeconômica, convicção política, gênero, orientação sexual, opção religiosa, etnia ou qualquer outro aspecto que possa caracterizar a preferência de um(ns) grupo(s) em detrimento de outro(s). Nessa perspectiva, o CEFET-RN deverá, permanentemente, buscar as condições que permitam o acesso e a permanência dos distintos grupos destinatários, assim como a garantia da qualidade dos processos educacionais desenvolvidos [...].

Além disso, é necessário extrapolar essa igualdade formal e caminhar na busca da eqüidade no acesso à educação, ao emprego, à saúde, ao meio ambiente saudável e a outros benefícios sociais, como forma de oportunizar tratamento diferenciado visando à promoção da igualdade entre desiguais. Assim, com o objetivo de manter o equilíbrio entre os distintos segmentos socioeconômicos que procuram matricular-se nas ofertas educacionais do CEFETRN e, também, com o intuito de contribuir para o fortalecimento da escola pública de educação básica, a Instituição deverá reservar, em todos os cursos abertos à comunidade, parte das vagas para estudantes provenientes da rede pública de educação.
\end{abstract}

Não se faz necessário, diante do que acabou de ser exposto, análises profundas sobre a vontade do CEFET-RN em realizar um processo educacional inclusivo. O trecho citado deixa bem claro e explícito as reais intenções da instituição de atender e permitir a permanência dos grupos sociais nela existentes e garantir uma educação de qualidade a todos.

Ainda nessa política, chama-se a atenção para o fato de que parte das vagas dos cursos oferecidos à comunidade pelo CEFET-RN serem reservadas a estudantes provenientes da rede pública de educação. Essas vagas são disputadas em um vestibular em que apenas esse tipo de estudante participa. Têm-se então uma atitude inclusiva que visa "resgatar" os 
estudantes que tiveram uma formação deficiente na rede pública. Se essa política não ocorresse, um número menos significativo de estudantes da rede pública estaria, devido a desigual formação propedêutica entre ensino público e privado, constituindo o quadro discente do CEFET-RN.

\section{Política de Inclusão das Pessoas com Necessidades Educacionais Especiais - PNEE}

Nesse item encontra-se um interessante material político-pedagógico sobre a inclusão social no campo educacional das pessoas com necessidades educacionais especiais. A sua introdução baseia-se - chegando até mesmo a transcrever alguns trechos (ver Brasil 1998, p. 17 e 23) - nos Parâmetros Curriculares Nacionais: adaptações curriculares, documento que trata de estratégias para a educação de alunos com necessidades educacionais especiais. Nessa parte do PPP, apresenta-se um conceito de inclusão escolar, seguido por encaminhamentos relacionados às condições dos alunos que devem ser respeitadas no processo inclusivo:

A inclusão escolar constitui uma proposta que representa valores simbólicos importantes, condizentes com a política de igualdade, em ambiente educacional favorável. Implica a inserção de todos, sem distinção de condições lingüísticas, sensoriais, cognitivas, físicas, emocionais, éticas, socioeconômicas e requer sistemas educacionais planejados e organizados que dêem conta da diversidade dos alunos e ofereçam respostas adequadas às suas características e necessidades. As diferenças são vistas não como obstáculos para o cumprimento da ação educativa, mas sim como fatores de enriquecimento.

Para por em práticas de inclusão, faz-se necessário o desenvolvimento de ações educacionais que removam barreiras (atitudinais, educacionais e arquitetônicas) para que a aprendizagem pretendida seja alcançada. (CEFET-RN, 2005, p. 113).

Semelhantemente, Laplane (2006, p.19) transcreve um trecho da "Sinopse estatística da educação básica: censo escolar 2004" que defende as seguintes situações que devem ser toleradas para o processo inclusivo:

[...] uma escola somente poderá ser considerada inclusiva quando estiver organizada para favorecer a cada aluno, independentemente de etnia, sexo, idade, deficiência, condição social ou qualquer outra situação. Um ensino significativo é aquele que garante o acesso ao conjunto sistematizado de conhecimentos como recursos a serem mobilizados. (BRASIL, 2004, p. 9)

Torna-se assim evidente que, além da forte referência aos PCNs, a introdução do item 6.2.3 do PPP do CEFET-RN segue os mesmos princípios que o documento de nível nacional citado por Laplane. No entanto, o primeiro documento, "Parâmetros Curriculares Nacionais: adaptações curriculares", não fora colocado nas referências do PPP, possivelmente por este estar ainda em construção. 
Após a introdução, surgem, no item em estudo, os aspectos integrantes da legislação da política de inclusão das pessoas com necessidades educacionais especiais. Esses aspectos estão fundamentados em duas legislações: o Decreto no. 3.298/99 e a Lei no. 9394/96 (atual Lei de Diretrizes e Bases da Educação, LDB) que versam sobre a Política Nacional para Integração da Pessoa com Deficiência e sobre o sistema educacional brasileiro, respectivamente. Com base nessas legislações, pode-se afirmar que os princípios que norteiam o PPP do CEFET-RN no âmbito legal são os mesmos princípios que regem a política nacional de inclusão das PNEE. Contudo, não se encontra nas referências do PPP, provavelmente pelo mesmo motivo da ausência da referência do documento, "Parâmetros Curriculares Nacionais: adaptações curriculares", a referência ao Decreto nº 3.298/99. Ele deveria estar nas referências, devido ao seu conteúdo sobre processo inclusivo e pelo fato do seguinte trecho ter sido transcrito e incorporado acertadamente ao PPP. Eis o trecho:

Art. 5 A Política Nacional para a Integração da Pessoa Portadora de Deficiência, em consonância com o Programa Nacional de Direitos Humanos, obedecerá aos seguintes princípios;

I - desenvolvimento de ação conjunta do Estado e da sociedade civil, de modo a assegurar a plena integração da pessoa portadora de deficiência no contexto socioeconômico e cultural;

II - estabelecimento de mecanismos e instrumentos legais e operacionais que assegurem às pessoas portadoras de deficiência o pleno exercício de seus direitos básicos que, decorrentes da Constituição e das leis, propiciam o seu bem-estar pessoal, social e econômico; e

III - respeito às pessoas portadoras de deficiência, que devem receber igualdade de oportunidades na sociedade por reconhecimento dos direitos que lhes são assegurados, sem privilégios ou paternalismos. (BRASIL, 1999).

Com relação à Lei no . 9394/96, o PPP do CEFET-RN baseou-se nos Arts. 4 e 59 para tratar do seu atendimento educacional às pessoas com necessidades educacionais especiais.

O artigo 4 fora parafraseado no PPP da seguinte forma: A Lei $\mathrm{n}^{\circ}$. 9.394/96 que estabelece as Diretrizes e Bases da Educação Nacional, em seu Art. 4 preceitua que o atendimento educacional especializado aos portadores de deficiência [grifo nosso] deve ser feito, preferencialmente, na rede regular de ensino. (CEFET-RN, 2005, p.114). Ao invés da paráfrase, este artigo deveria ter sido transcrito ou citado de forma que as palavras originais fossem mantidas. Isto seria importante, pois a expressão portadores de deficiência, que para alguns autores assume um caráter pejorativo, não seria utilizada e em seu lugar estaria a expressão educandos com necessidades especiais - expressão original do artigo 4. Apesar da Política Nacional para a Integração da Pessoa Portadora de Deficiência, que fundamenta (como fora comentado acima) o PPP do CEFET-RN, fazer uso dessa expressão imprópria às PNEE, isto não implica que os idealizadores do PPP tenham que manter essa expressão. Como esse projeto é próprio do CEFET-RN, cabe a ele uma redação mais adequada dos termos envolvidos no processo educacional inclusivo.

Com base ainda na Lei nº 9394/96, poderiam também ser abordados no PPP os Arts. 58 e 60. O Art. 58 seria utilizado para atribuir ao PPP à definição legal de educação especial e a necessidade de serviços de apoio especializados a esse tipo de educação. 
Art. 58. Entende-se por educação especial, para os efeitos desta Lei, a modalidade de educação escolar, oferecida preferencialmente na rede regular de ensino, para educandos portadores de necessidades especiais.

$\S 1^{\circ}$ Haverá, quando necessário, serviços de apoio especializado, na escola regular, para atender as peculiaridades da clientela de educação especial (BRASIL, 1996).

Já o Art. 60 reforçaria a idéia que uma educação inclusiva não é obrigação única do CEFET-RN, mas que também depende da atuação do poder público.

Art. 60. Os órgãos normativos dos sistemas de ensino estabelecerão critérios de caracterização das instituições privadas sem fins lucrativos, especializadas e com atuação exclusiva em educação especial, para fins de apoio técnico e financeiro pelo Poder público.

Parágrafo único. O poder Público adotará, como alternativa preferencial, a ampliação do atendimento aos educandos com necessidades especiais na própria rede pública regular de ensino, independentemente do apoio às instituições previstas neste artigo (BRASIL, 1996).

$\mathrm{Na}$ finalização do item 6.2.3, têm-se uma descrição de algumas ações que objetivam "promover o acesso e a inclusão das pessoas com necessidades educacionais especiais em todas as ofertas educacionais do CEFET/RN, fundamentado nos princípios do direito ao exercício da cidadania e da integração ao mundo do trabalho" (CEFET-RN, 2005, p. 114). Essas ações estão de acordo com as propostas de um processo educacional inclusivo, pois prioriza não somente a acessibilidade de suas estruturas físicas, do mobiliário e de seus equipamentos, visando adequações, como também a adaptação dos currículos, dos procedimentos metodológicos e avaliativos do CEFET-RN.

\section{Política de Educação à Distância}

Neste item do PPP do CEFET-RN, a instituição preocupou-se em explicitar que um dos princípios gerais que norteiam a implantação da educação à distância é a necessidade de ampliar a oferta educacional àquelas pessoas que encontram-se impedidas seja fisicamente ou socioeconomicamente de participarem de uma educação presencial. No trecho abaixo, têm-se claramente essa preocupação.

Nesse sentido, considerando-se a educação como fenômeno social contextualizado, não se pode deixar de pensar na dimensão continental do nosso país e na quantidade de profissionais excluídos do processo produtivo, devido, entre outros fatores, às diferenças sócio-econômicas, à dificuldade de acesso aos locais de estudo, à pouca disponibilidade de tempo (CEFET-RN, 2005, p. 116-117).

Ainda neste item 6.2.4, aparece como um dos princípios para a educação profissional e tecnológica à distância do CEFET-RN, o comprometimento com a educação inclusiva. 
Princípios para a Educação Profissional e Tecnológica em EaD no CEFET-RN

$[\ldots$.

b. Comprometer-se com a educação inclusiva.

Atualmente existe uma preocupação cada vez maior de ampliar o acesso à educação, tanto quantitativamente quanto qualitativamente, das pessoas menos favorecidas da sociedade no que se refere à situação econômica ou as pessoas portadoras de necessidades educacionais especiais. Por outro lado, a formação continuada de trabalhadores para a permanência no mundo laboral é também um elemento a ser considerado como parte da educação que se preocupa com a responsabilidade social da Instituição com seus egressos e com a sociedade em geral e, portanto, com a inclusão social (CEFET-RN, 2005, p. 118-119).

Pode-se afirmar assim que a preocupação do CEFET-RN em promover um processo educacional inclusivo vai muito além das dependências e muros da instituição. A vontade e a necessidade de atingir a sociedade de forma inclusiva com o seu projeto educacional, faz com que o CEFET-RN amplie sua função social e atue na educação à distância.

\section{CONSIDERAÇÕES FINAIS}

A análise do PPP do CEFET-RN apontou que há uma preocupação da Instituição em realizar a prática da inclusão social por meio de diversos elementos existentes no tríplice universo humano e na área educacional. O processo educacional inclusivo desta instituição revelou-se, por meio do seu PPP, como um processo bem consolidado teoricamente e que pressupõe bons resultados em sua efetivação. A concepção institucional de cultura, a base sócio-cultural do diálogo, a base epistemológica da política da igualdade e a educação à distância foram os maiores destaques encontrados para exemplificar o esforço e a vontade que o CEFET-RN tem e demonstra para alcançar seus objetivos por um processo educacional inclusivo.

A análise também mostrou que o CEFET-RN, alicerçando-se nos princípios do direito ao exercício da cidadania e da integração, está de acordo com a Lei $n^{\circ}$. 9394/96 e com o Decreto $\mathrm{n}^{\mathrm{o}}$. 3.298/99 sobre a Política Nacional para a Integração da Pessoa com Deficiência para promover o acesso e a inclusão das pessoas com necessidades educacionais especiais.

É fato que medidas como essas que foram citadas durante todo o artigo não são suficientes para que todos os objetivos que permeiam a educação inclusiva sejam alcançados. Elas são importantes, contudo, se não houver uma participação ativa tanto da comunidade externa do CEFET-RN, quanto das pessoas que compõe essa instituição, a implantação das políticas de inclusão no processo educacional inclusivo do CEFET-RN, corre um grande risco de não sair do papel. Para que isso não ocorra é necessário que a instituição se autoavalie durante esse período de construção e de implantação do PPP.

É necessário avaliar para detectar a diferença entre o planejado/previsto e o realizado no sentido de corrigir essas diferenças. É necessário avaliar 
para identificar possíveis falhas no próprio projeto e, dessa forma, redefinir conceitos, metas e objetivos, enfim é necessário avaliar para estabelecer um diálogo permanente entre a teoria (o projeto) e a prática (a implementação do projeto) (CEFET-RN, 2005, p. 120-121).

Essas palavras reforçam o porquê de se auto-avaliar e o como trilhar um caminho que leva ao êxito.

Diante de tudo isso, conclui-se que se faz necessário que políticas educacionais sejam adotadas, saindo-se do campo teórico para a prática. As leis, as políticas e os projetos são muito importantes para introduzir e sustentar esse ideal da educação inclusiva, porém torna-se urgente que toda essa teoria entre na rotina das instituições. Do contrário, estará se criando uma inclusão às avessas, que poderá dificultar ou até mesmo impedir a implementação das medidas a favor da inclusão social.

\section{REFERÊNCIAS}

BRASIL. Decreto nº 3.29820 de dezembro de 1999. Política Nacional para Integração da Pessoa com Deficiência. Disponível em: <http://www.mj.gov.br/sedh/ct/corde/dpdh/corde/dec3298.asp> Acesso em: 19/01/2007. Lei $\mathrm{n}^{\circ}$ 9.394, de 20 de dezembro de 96 - LDB. Estabelece as diretrizes e bases da Educação Nacional. Disponível em: <http://portal.mec.gov.br/seesp/arquivos/pdf/lei9394_ldbn1.pdf>. Acesso em: 19/01/2007. Ministério da Educação, Secretaria de Educação Média e Tecnológica. Parâmetros curriculares nacionais: Adaptações Curriculares. Brasília: Ministério da Educação, 1998. Disponível em: <http://200.156.28.7/Nucleus/media/common/Downloads_PCN.PDF>. Acesso em: 19 jan. 2007.

CENTRO FEDERAL DE EDUCAÇÃO TECNOLÓGICA DO RIO GRANDE DO NORTE.

Projeto Pedagógico do CEFET-RN. Natal: CEFET-RN, 2005.

FIGUEIRA, Emílio. Inclusão social: afinal o que é? Disponível em: $<$ http://www.sciencenet.com.br/sciencepress/67/cientifico_67b.htm >. Acesso em: 15 jan. 2007.

FREIRE, P. Pedagogia da autonomia. 28 ed. São Paulo: Paz e Terra, 1996.

LAPLANE, Adriana. Uma análise das condições para a implementação de políticas de educação inclusiva no Brasil e na Inglaterra. Disponível em: <http://www.scielo.br/pdf/es/v27n96/a04v2796.pdf>. Acesso em: 15 jan. 2007.

MANTOAN, M. T. E. Uma escola de todos, para todos e com todos: o mote da inclusão. Disponível em: $<$ http://www.lite.fae.unicamp.br/papet/2002/nt/ta1.5.htm>. Acesso em: 15 jan. 2007.

SEVERINO, A. J. A compreensão filosófica do educar e a construção da filosofia da educação. In: ROCHA, Dorothy (org.) Filosofia da educação: diferentes abordagens. Campinas: Papirus, 2004, p. 9-36 (coleção Papirus Educação). 
SOUSA, José Vieira de; CORRÊA, Juliane. Projeto pedagógico: a autonomia construída no cotidiano da escola. In: DAVIS, Cláudia; VIEIRA, Sofia Lerche. et al. (Org). Gestão da escola: desafios a enfrentar. Rio de Janeiro: DP\&A, 2002. 